\title{
A STUDY OF CERTAIN ASPECTS OF BLOOD COAGULATION IN THE POSTOPERATIVE STATE IN CONGESTIVE HEART FAILURE AND IN THROMBOPHLEBITIS
}

\author{
By NOBLE O. FOWLER, ${ }^{1}$ WITH THE TECHNICAL ASSISTANCE OF SHIRLEY ROEHM \\ AND HAROLD PERLMAN \\ (From the Cardiac Laboratory, Cincinnati General Hospital, and the Department of Internal \\ Medicine, University of Cincinnati)
}

(Received for publication January 18, 1949)

In recent years a number of tests have been designed for the purpose of detection of accelerated blood coagulation. Among these are the lusteroid tube coagulation test $(1-4)$, the silicone tube coagulation test (5), the modified clot retraction test (6), the modified Lee-White clotting test, employing three test tubes instead of one (7), the heparin retarded coagulation test of Waugh and Ruddick $(8,9)$, the heparin tolerance test $(10,11)$, and the prothrombin time determination, using both whole and dilute plasma (12-14).

The study reported herewith was undertaken for the following purposes. First, it was desired to ascertain whether or not there is any correlation among the various tests themselves. Second, it was decided to determine whether any of these tests can be used to predict thrombophlebitis in patients. Finally, the incidence and duration of hypercoagulability in the postoperative state was studied, as well as the incidence of hypercoagulability in congestive heart failure. Incident to doing these studies, observations were made on the effect of variation of tube size and temperature upon the clotting time of blood in the Lee-White test. Further, in doing the heparin tolerance test, blood was withdrawn almost simultaneously from the vein into which the heparin was injected and from a vein of the opposite arm. Clotting times were run on each sample and the results were compared.

\section{MATERIAL}

For the study on postoperative patients, a group of 29 patients in the Cincinnati General Hospital who had had recent major surgical operations was selected at random. These 29 patients and three additional patients having acute thrombophlebitis were used to determine the correlation among the various tests. The problem of hypercoagulability in congestive heart failure was studied in 27

1 National Institute of Health Postdoctorate Research Fellow. patients suffering from cardiac insufficiency on the medical wards of the Cincinnati General Hospital. A group of house officers, nurses, technicians, and ambulatory psychiatric patients were used as normal controls. Persons from both the control group and from the postoperative group were used to study the effect of variation in temperature and tube size upon the Lee-White clotting test. Persons from both groups were also used to study the effect of the veins chosen in performing the heparin tolerance test.

\section{METHODS}

The 29 postoperative patients and the three patients having acute thrombophlebitis were each studied by means of six tests which were run simultaneously. The same series of six tests was repeated on seven of the postoperative group later in their postoperative courses. The six tests employed were the modified Lee-White clotting test, the lusteroid tube coagulation test, the prothrombin time on whole and on $12.5 \%$ plasma, the Waugh-Ruddick heparin retarded coagulation test, and the heparin tolerance test. The 27 patients suffering from congestive heart failure were studied by means of the lusteroid tube coagulation test and the modified Lee-White test using three dry test tubes and an oiled syringe. Fifty of the control group were studied with the lusteroid tube coagulation test and the modified Lee-White test, using three test tubes and an oiled syringe. Twenty of the control group, all ambulatory psychiatric patients, were studied with the heparin tolerance test and the modified LeeWhite test, using three saline-rinsed test tubes and a saline-rinsed syringe. The whole and dilute plasma prothrombin times were studied in 28 ambulatory psychiatric patients. The Waugh-Ruddick test was studied by means of 25 tests on a series of 15 persons in the control group.

\section{PROCEDURE}

\section{Modified Lee-White test}

This test was run essentially as described by Lee and White (15), with the exception that three test tubes were used instead of one. The second tube was not tilted until clotting had occurred in the first, and the third tube was not tilted until clotting had occurred in the second. The time required for clotting in the third tube was taken as the clotting time. This test was run in a constant tem- 
perature water bath at $37^{\circ} \mathrm{C}$ as suggested by Quick (16). This test was also run on each patient using three dry test tubes and an oiled syringe.

\section{Prothrombin time on whole and $12.5 \%$ plasma}

The method described by Quick (17) was employed, using Squibb thromboplastin.

\section{Lusteroid tube coagulation test}

The method used was similar to that of Kadish $(1,2)$, except that three tubes were used instead of one, the reading being taken from the third tube. The tests were run in a constant temperature water bath at $37^{\circ} \mathrm{C}$. Blood was used only if obtained at the first attempt at venipuncture. Specimens were discarded if bubbling or frothing occurred in the syringe. The lusteroid tubes were 12.5 $\mathrm{mm}$. in diameter. They were cleaned with sodium lauryl sulfonate, as recommended by Kadish $(1,2)$.

\section{Waugh-Ruddick heparin retarded coagulation test}

This test often shows acceleration of coagulation when the Lee-White test is normal. The method employed was that described by the original authors $(8,9)$, except that all tests were run in a water bath at $22.5^{\circ} \mathrm{C}$, as recommended by Whittaker (18). This author found that a rise in temperature caused much more rapid clotting in the Waugh-Ruddick test; we have had a similar experience. Whittaker selected $22.5^{\circ}$ as the average winter room temperature. Waugh and Ruddick did their tests at room temperature $(8,9)$. He found clotting times in normals comparable to those of Waugh and Ruddick when the tubes containing the blood were placed in a water bath at a temperature of $22.5^{\circ} \mathrm{C}$ (18). The criterion of increased coagulability in this test was that suggested by Ogura (19), namely, a coagulation time of 60 minutes or less in each of the last three test tubes employed.

\section{Heparin tolerance test}

Hagedorn and Barker's (11) modification of the test of deTakats (10) was employed. However, in consideration of the marked effect of temperature variation upon the clotting time of blood $(16,18)$, the tests were done in a constant temperature water bath at $37^{\circ} \mathrm{C}$. Three test tubes, each $8 \mathrm{~mm}$. by $75 \mathrm{~mm}$., were employed.
As suggested by Hagedorn and Barker (11), one sample of blood was drawn 10 minutes after the injection of 25 $\mathrm{mg}$. of heparin in $2.5 \mathrm{cc}$. of solution intravenously. The heparin was injected at a constant rate, requiring 30 seconds for its administration.

\section{RESULTS}

The findings in the control group will be given first. These are shown in Table I. In 50 controls, the range for the modified Lee-White test, using an oiled syringe, was from 9 to 23.5 minutes; the range for clotting in lusteroid was from 19 to 40 minutes in this group. In 20 controls, the range for the modified Lee-White test, using salinerinsed glassware, was from 9 to 21 minutes. The mean for the 20 determinations was $11.58 \mathrm{~min}$ utes when saline-rinsed tubes and syringes were employed; the mean for 50 similar tests using an oiled syringe and dry test tubes was 14.77 minutes. The standard deviation for the 50 determinations using oiled syringes was 3.34 minutes. The standard deviation for the 20 determinations using a saline-rinsed syringe was 4.36 minutes. The standard error of the difference between the two means of 14.77 minutes and 11.58 minutes was found to be 1.08 minutes. The observed difference was 3.19 minutes. Since the observed difference in the means was three times the standard error of the difference, this was felt to be a significant finding. This difference would occur by chance only once in 370 tests. Ten minutes after the injection of $25 \mathrm{mg}$. of heparin intravenously, the modified Lee-White clotting time was increased from two to slightly more than four times that before heparin.

Among 28 control ambulatory psychiatric patients, the range for the prothrombin time run on whole plasma was from 11.5 to 16.00 seconds. The range for the prothrombin time on $12.5 \%$ plasma was 26 to 37 seconds; the range for the difference

TABLE I

Results of various coagulation tests in the control group

\begin{tabular}{|c|c|c|c|}
\hline Name of test & $\begin{array}{l}\text { Number of } \\
\text { persons }\end{array}$ & Range & Mean \\
\hline $\begin{array}{l}\text { Lee-White (oiled syringe) } \\
\text { Lee-White (saline-rinsed syringe) } \\
\text { Heparin tolerance test }\end{array}$ & $\begin{array}{l}50 \\
20 \\
20\end{array}$ & $\begin{array}{l}9 \text { to } 23.5 \mathrm{~min} \text {. } \\
9 \text { to } 21 \mathrm{~min} \text {. } \\
\text { Clotting time increased }\end{array}$ & $\begin{array}{l}14.77 \mathrm{~min} . \\
11.58 \mathrm{~min} .\end{array}$ \\
\hline $\begin{array}{l}\text { Lusteroid tube clotting test } \\
\text { Prothrombin time (whole plasma) } \\
\text { Prothrombin time ( } 12.5 \% \text { plasma). }\end{array}$ & $\begin{array}{l}50 \\
28 \\
28\end{array}$ & $\begin{array}{l}19 \text { to } 40 \mathrm{~min} \text {. } \\
11.5 \text { to } 16 \mathrm{sec} \text {. } \\
26 \text { to } 37 \mathrm{sec} \text {. }\end{array}$ & $13.5 \mathrm{sec}$. \\
\hline
\end{tabular}


TABLE II

Summary of findings in 29 postoperative cases

\begin{tabular}{|c|c|c|c|c|c|c|c|}
\hline Operation & P. O. day & $\begin{array}{l}\text { Pro. time } \\
\text { whole }\end{array}$ & $\begin{array}{l}\text { Pro. time } \\
12.5 \%\end{array}$ & $\begin{array}{l}\text { Lee-White } \\
\text { saline } \\
37^{\circ} \mathrm{C}\end{array}$ & Lust. & $\begin{array}{l}\text { Heparin tol. } \\
37^{\circ} \mathrm{C}\end{array}$ & $\begin{array}{l}\text { Waugh- } \\
\text { Ruddick } \\
22.5^{\circ} \mathrm{C}\end{array}$ \\
\hline $\begin{array}{l}\text { 1. Append. } \\
\text { 2. Hysterect. } \\
\text { 3. Nephrect. } \\
\text { 4. Hernia } \\
\text { 5. Hernia } \\
\text { 6. Nephrect. } \\
\text { 7. Hysterect. } \\
\text { 8. Append. } \\
\text { 9. Hernia } \\
\text { 10. Hernia } \\
\text { 11. Gunshot colon } \\
\text { 12. Gunshot colon } \\
\text { 13. Hernia } \\
\text { 14. Stab of abdomen } \\
\text { 15. Append. } \\
\text { 16. Hysterect. } \\
\text { 17. Hysterect. } \\
\text { 18. Append. } \\
\text { 19. Hernia } \\
\text { 20. Hernia } \\
\text { 21. Gunshot bowel } \\
\text { 22. Gunshot bowel } \\
\text { 23. Stab of bowel } \\
\text { 24. Stab of abdomen } \\
\text { 25. Append. } \\
\text { 26. Append. } \\
\text { 27. Gunshot bowel } \\
\text { 28. Hernia } \\
\text { 29. Perf. ulcer }\end{array}$ & $\begin{array}{l}6 \\
6 \\
6 \\
5 \\
4 \\
1 \\
3 \\
4 \\
4 \\
5 \\
3 \\
4 \\
2 \\
3 \\
2 \\
9 \\
3 \\
4 \\
3 \\
4 \\
6 \\
2 \\
6 \\
2 \\
1 \\
1 \\
4 \\
2 \\
6\end{array}$ & $\begin{array}{c}0 \\
0 \\
0 \\
0 \\
0 \\
0 \\
0 \\
0 \\
\text { acc } \\
\text { acc } \\
\text { acc } \\
0 \\
0 \\
0 \\
0 \\
0 \\
0 \\
0 \\
0 \\
0 \\
0 \\
0 \\
0 \\
0 \\
0 \\
0 \\
\text { acc } \\
0 \\
\text { acc }\end{array}$ & $\begin{array}{c}0 \\
0 \\
0 \\
0 \\
0 \\
0 \\
\text { acc } \\
0 \\
0 \\
0 \\
\text { acc } \\
0 \\
0 \\
0 \\
0 \\
0 \\
0 \\
0 \\
\text { acc } \\
0 \\
0 \\
0 \\
0 \\
0 \\
0 \\
0 \\
0 \\
0 \\
0\end{array}$ & $\begin{array}{c}0 \\
0 \\
0 \\
\text { acc } \\
0 \\
0 \\
\text { acc } \\
0 \\
0 \\
0 \\
0 \\
0 \\
0 \\
0 \\
0 \\
0 \\
0 \\
0 \\
\text { acc } \\
0 \\
0 \\
0 \\
0 \\
0 \\
0 \\
0 \\
0 \\
0 \\
0\end{array}$ & $\begin{array}{c}0 \\
0 \\
\text { acc } \\
0 \\
\text { acc } \\
0 \\
0 \\
\text { acc } \\
0 \\
\text { acc } \\
0 \\
0 \\
0 \\
0 \\
0 \\
\text { acc } \\
0 \\
0 \\
\text { acc } \\
0 \\
0 \\
0 \\
\text { acc } \\
\text { acc } \\
0 \\
\text { acc } \\
\text { acc } \\
0 \\
0\end{array}$ & $\begin{array}{c}0 \\
0 \\
0 \\
0 \\
0 \\
\text { acc } \\
- \\
\text { acc } \\
0 \\
0 \\
0 \\
0 \\
\text { acc } \\
0 \\
0 \\
0 \\
0 \\
0 \\
0 \\
0 \\
0 \\
\text { acc } \\
0 \\
\text { acc } \\
0 \\
0 \\
\text { acc } \\
0\end{array}$ & $\begin{array}{c}\text { acc } \\
\text { acc } \\
\text { acc } \\
0 \\
\text { acc } \\
\text { acc } \\
\text { acc } \\
\text { acc } \\
\text { acc } \\
\text { acc } \\
\text { acc } \\
\text { acc } \\
0 \\
\text { acc } \\
0 \\
\text { acc } \\
\text { acc } \\
\text { acc } \\
\text { acc } \\
0 \\
0 \\
\text { acc } \\
0 \\
0 \\
0 \\
\text { acc } \\
0 \\
0 \\
\text { acc }\end{array}$ \\
\hline
\end{tabular}

Note: acc indicates acceleration

0 indicates no acceleration

- indicates that the test was not run

between the whole and dilute plasma prothrombin times was from 14 to 22 seconds.

Acceleration was considered present in any test when the result obtained was lower (i.e., less time) than was found in any control test of the same method. Of the 29 postoperative patients, acceleration was found as follows : by Waugh-Ruddick, 19 showed acceleration; by lusteroid, 10 ; by heparin tolerance, six ; by whole plasma prothrombin time, five; by $12.5 \%$ plasma prothrombin time, three; by modified Lee-White test run in salinerinsed glass, three. The results are summarized in Table II. As seen in Table II, the correlation among the various tests was poor. Of 10 patients showing abnormal tests in lusteroid, seven showed abnormal Waugh-Ruddick tests. However, of six patients with abnormal heparin tolerance, only two had accelerated Waugh-Ruddick tests, and only two had accelerated clotting in lusteroid. Of five patients having abnormally short whole plasma prothrombin times, four showed abnormal Waugh-Ruddick tests, but only two had accelerated clotting in lusteroid. The only patient among the 29 tested who developed venous thrombosis had normal values for all tests. This patient was a 42 year old colored man, who had had a hernia repaired eight days prior to the thrombosis. The clotting tests were performed five days prior to the occurrence of the thrombosis.

In order to ascertain how long the state of accelerated coagulation may persist after operation, the same series of six tests was repeated on seven of the 29 patients later in their postoperative courses. The results are shown in Table III. As may be seen in the table, evidence of hypercoagulability was found as late as 12 days after operation in some instances.

Our clotting times after $25 \mathrm{mg}$. of heparin were shorter than those obtained by Hagedorn and Barker (11), probably because our tests were performed at $37^{\circ} \mathrm{C}$, whereas their tests were performed at room temperature, which is generally much lower. In order to study the effect of temperature upon the results obtained in this test, we 
TABLE III

Persistence of hypercoagulability following operation

\begin{tabular}{|c|c|c|c|c|c|c|c|}
\hline Operation & P. O. day & $\begin{array}{l}\text { Pro. time } \\
\text { whole }\end{array}$ & $\begin{array}{c}\text { Pro. time } \\
12.5 \%\end{array}$ & $\begin{array}{l}\text { Lee-White } \\
\text { saline }\end{array}$ & Lust. & Heparin tol. & $\begin{array}{l}\text { Waugh- } \\
\text { Ruddick }\end{array}$ \\
\hline 1. Hernia & $\begin{array}{r}2 \\
12\end{array}$ & $\begin{array}{l}\text { sec. } \\
15 \\
12.5\end{array}$ & $\begin{array}{l}\text { sec. } \\
30 \\
28.5\end{array}$ & $\begin{array}{r}\min . \\
9 \frac{1}{2} \\
17 \frac{1}{2}\end{array}$ & $\begin{array}{l}\min . \\
31 \frac{1}{2} \\
26\end{array}$ & $\begin{array}{l}\min . \\
17 \frac{1}{2}^{*} \\
36\end{array}$ & $\begin{array}{l}\min . \\
66 \\
72\end{array}$ \\
\hline 2. Hysterect. & $\begin{array}{r}3 \\
11\end{array}$ & $\begin{array}{l}12.5 \\
11.5\end{array}$ & $\begin{array}{l}30.5 \\
23.5^{*}\end{array}$ & $\begin{array}{r}9 \\
13\end{array}$ & $\begin{array}{l}27 \\
29\end{array}$ & $\begin{array}{l}22 \\
42\end{array}$ & $\begin{array}{l}52^{*} \\
48^{*}\end{array}$ \\
\hline 3. Gunshot bowel & $\begin{array}{r}4 \\
12\end{array}$ & $\begin{array}{l}10.5^{*} \\
14\end{array}$ & $\begin{array}{l}27 \\
33.5\end{array}$ & $\begin{array}{l}15 \\
15 \frac{1}{2}\end{array}$ & $\begin{array}{l}16^{*} \\
24\end{array}$ & $\begin{array}{l}49 \\
22^{*}\end{array}$ & $\begin{array}{l}64 \\
64\end{array}$ \\
\hline 4. Hernia & $\begin{array}{l}2 \\
9\end{array}$ & $\begin{array}{l}12.5 \\
12.5\end{array}$ & $\begin{array}{l}31.5 \\
31\end{array}$ & $\begin{array}{l}27 \\
10\end{array}$ & $\begin{array}{l}32 \\
37\end{array}$ & $\begin{array}{l}45 \\
36\end{array}$ & $\begin{array}{l}82 \\
68\end{array}$ \\
\hline 5. Perf. ulcer & $\begin{array}{r}6 \\
12\end{array}$ & $\begin{array}{l}11^{*} \\
16.5\end{array}$ & $\begin{array}{l}26 \\
45\end{array}$ & $\begin{array}{l}10 \\
16\end{array}$ & $\begin{array}{l}19 \\
27\end{array}$ & $\begin{array}{l}27 \\
24^{*}\end{array}$ & $\begin{array}{l}50^{*} \\
58^{*}\end{array}$ \\
\hline 6. Append. & $\begin{array}{r}4 \\
11\end{array}$ & $\begin{array}{l}14 \\
12.5\end{array}$ & $\begin{array}{l}35 \\
35\end{array}$ & $\begin{array}{l}11 \frac{1}{2} \\
14\end{array}$ & $\begin{array}{l}30 \\
29\end{array}$ & $\begin{array}{l}28 \\
31\end{array}$ & $\begin{array}{l}54^{*} \\
66\end{array}$ \\
\hline 7. Gunshot liver & $\begin{array}{r}2 \\
10\end{array}$ & $\begin{array}{l}12 \\
16\end{array}$ & $\begin{array}{l}30 \\
34.5\end{array}$ & $\begin{array}{l}12 \\
10\end{array}$ & $\begin{array}{l}25 \\
26\end{array}$ & $\begin{array}{l}48 \\
62 \dagger\end{array}$ & $\begin{array}{l}60^{*} \\
58^{*}\end{array}$ \\
\hline
\end{tabular}

* Accelerated value

† Abnormal hypocoagulability

ran clotting times on samples of blood drawn 10 minutes after giving $25 \mathrm{mg}$. of heparin intravenously to each of 10 patients. One part of the sample was tested at $22.5^{\circ}$, the average winter room temperature, and the other portion was done at $37^{\circ}$. As may be seen in Table IV, the clotting time was appreciably longer at $22.5^{\circ}$ in all instances save two. The average clotting time at $22.5^{\circ}$ was 26.5 minutes, and at $37^{\circ}, 13.4$ minutes.

In order to study the effect of test tube size upon the results obtained in doing the Lee-White clotting time, this test was done in glass tubes of

TABLE IV

The effect of temperature on the heparin tolerance test *

\begin{tabular}{|c|c|c|}
\hline $\begin{array}{c}\text { Before } \\
\text { heparin } \\
\text { min. }\end{array}$ & $\begin{array}{c}10 \text { min. } \\
\text { after } \\
\text { heparin } \\
37^{\circ} \mathrm{C} \\
\text { min. }\end{array}$ & $\begin{array}{c}10 \mathrm{~min} . \\
\text { after } \\
\text { heparin } \\
22.5^{\circ} \mathrm{C} \\
\text { min. }\end{array}$ \\
\hline 1. $7 \frac{1}{2}$ & 22 & 38 \\
\hline 2. 9 & 11 & 52 \\
\hline 4. 7 & 12 & $\begin{array}{l}12 \\
27 \frac{1}{2}\end{array}$ \\
\hline 5. 9 & 17 & 42 \\
\hline $\begin{array}{l}0.6 \\
7.7\end{array}$ & $\begin{array}{l}18 \\
16\end{array}$ & $\begin{array}{l}18 \\
201\end{array}$ \\
\hline 8. - & 10 & $14^{\circ}$ \\
\hline 9. - & $12 \frac{1}{2}$ & 12 \\
\hline 10. - & 11 & 29 \\
\hline
\end{tabular}

* Blood specimens were drawn 10 minutes after $25 \mathrm{mg}$. heparin intravenously, and were divided into two portions. Most of these are abnormal cases, i.e., postoperative cases. two different sizes, one $8 \mathrm{~mm}$. by $75 \mathrm{~mm}$. and the other, $13 \mathrm{~mm}$. by $100 \mathrm{~mm}$., using identical samples of blood. As shown in Table V, this procedure was performed in 14 instances. It may be seen that the clotting times were longer in the small tubes in nine instances; the clotting times were equal in one case; in the four remaining instances the clotting times were longer in the large tubes. Both Kadish (1) and Quick (16) found clotting times to be longer in large than in small glass tubes.

Whether or not the veins selected in performing the heparin tolerance test affected the result was also studied. In 14 instances, the one tube Lee-

TABLE V

The effect of tube size on the three tube Lee-White clotting test

$\begin{array}{cc}\begin{array}{c}\text { Tube } 8 \mathrm{~mm} . \text { by } \\ 75 \mathrm{~mm} . \\ \text { min. }\end{array} & \begin{array}{c}\text { Tube } 13 \mathrm{~mm} . \text { by } \\ 100 \mathrm{~mm} . \\ \text { min. }\end{array} \\ 12 & 10 \\ 13 & 10 \\ 15 & 13 \\ 11 & 9 \\ 11 & 11 \\ 12 & 6 \frac{1}{2} \\ 16 & 12 \\ 13 & 10 \frac{1}{2} \\ 10 & 11 \frac{1}{2} \\ 21 & 11 \\ 10 & 11 \\ 12 & 13 \frac{1}{2} \\ 10 & 10 \frac{1}{2} \\ 11 & 10 \frac{1}{2}\end{array}$


White test was performed 10 minutes after injecting $25 \mathrm{mg}$. of heparin intravenously. Blood was drawn almost simultaneously from the vein into which the heparin was given, and from the vein of the opposite arm. As seen in Table VI, the results were the same or nearly so in seven instances. In six cases, the clotting times were considerably longer on blood drawn from the vein which had received the heparin. In one instance, the blood drawn from the vein receiving the heparin did not clot after 12 hours. In one case, the clotting time was significantly shorter on blood taken from the vein receiving the heparin. This finding would seem to imply that in some instances there is retained in the vein injected with a foreign substance a larger proportion of substance than is found in the general circulation.

TABLE VI

The effect of veins used upon the results of the heparin tolerance test

\begin{tabular}{c|c|c|c}
\hline \hline & Before heparin & $\begin{array}{c}10 \text { min. after } \\
\text { heparin same } \\
\text { vein }\end{array}$ & $\begin{array}{c}10 \text { min. after } \\
\text { heparin op- } \\
\text { posite arm }\end{array}$ \\
\cline { 2 - 3 } 1 & min. & 39 min. & min. \\
2 & 6 & 12 hours plus & 12 \\
3 & $6 \frac{1}{2}$ & 14 min. & 14 \\
4 & $8 \frac{1}{2}$ & $8^{*}$ & $9 *$ \\
5 & 7 & $73 \dagger$ & $50 \dagger$ \\
6 & 7 & $13 \frac{1}{2}$ & 12 \\
7 & 7 & $22 \frac{1}{2}$ & 24 \\
8 & $5 \frac{13}{2}$ & 12 & 12 \\
9 & 5 & 71 & $5^{*}$ \\
10 & 5 & $10^{*}$ & $16^{*}$ \\
11 & - & 13 & $12 \frac{1}{2}$ \\
12 & - & 10 & 11 \\
13 & - & & \\
14 & - & &
\end{tabular}

* Acceleration.

$+50 \mathrm{mg}$. heparin given instead of $25 \mathrm{mg}$.

Note: Each patient received $25 \mathrm{mg}$. heparin intravenously. After 10 minutes, one tube Lee-White clotting times were run on blood drawn almost simultaneously from the vein receiving the heparin and from the vein of the opposite arm.

\section{DISCUSSION}

The clotting mechanism in postoperative patients was studied by Potts and Pearl (20), Dawbarn, Earlham, and Evans (21), and by Shapiro Sherwin, and Gordimer (22). These investigators found that the platelet count tended to fall during the first three days postoperatively, but that it began to rise on the sixth postoperative day, and reached a peak on the tenth to 14 th postoperative day. They found little change in the clotting time as determined by the usual methods.

The abnormalities in the clotting mechanism found by us do not parallel the changes in the platelet count found by the above investigators; in general we found abnormalities in clotting earlier in the postoperative course in this study. Not only were the manifestations of derangements in the clotting mechanism found earlier here, but the change seemed to be greater earlier in the postoperative course than in the 10 to 14 day postoperative period when the maximum changes in the platelet count were found. However, as seen in Table III some cases still showed acceleration of clotting as long as 12 days after operation.

The finding of accelerated coagulation as judged by the Waugh-Ruddick test in 19 of the 29 postoperative patients is in keeping with the findings of Waugh and Ruddick (9), whose study of postoperative patients revealed accelerated coagulation 24 hours after operation; this acceleration was present seven days following operation. Our finding of acceleration of coagulation in two-thirds of 29 postoperative patients, a finding which persisted at least 12 days after operation in some cases, may be considered in regards to possible routine postoperative anticoagulant therapy.

The Waugh-Ruddick test seemed most sensitive of the tests employed in detecting the effect of operative trauma. In this connection, it is of interest to note that Flinn (23), following the administration of digitalis in man, found acceleration of coagulation as shown by the Waugh-Ruddick test, whereas the Lee-White test and the prothrombin time on whole and dilute plasma showed no change. The extreme sensitivity of the WaughRuddick test is shown by its acceleration in response to such procedures as operative trauma and digitalization; this would seem to detract from its value in the prediction or diagnosis of venous thrombosis. The non-specificity of this test is further illustrated by the fact that Waugh and Ruddick found that bed rest alone caused acceleration of coagulation (9).

It is of interest to note the lack of correlation between the Waugh-Ruddick test and the heparin tolerance test, since heparin is used to prolong the coagulation of blood in both instances, in the former in vitro and in the latter in vivo. In partial explanation of this finding, the statements of 
Best and Jaques (24) may be cited. These writers state that if there is mixture of the same amounts of heparin and blood in vivo and in vitro, the clotting time will be longer in vivo if moderate amounts of heparin are used. Best and Jaques also state that the renal threshold for heparin is quite low, and that there is rapid excretion of heparin into the urine if large doses are given intravenously. Further, even if heparin is not excreted into the urine, it disappears rapidly from the blood. Thus, variation in the rate of heparin destruction and heparin excretion have to be reckoned with in performing the heparin tolerance test. Since these factors are not operative in the Waugh and Ruddick test, the failure of the two tests to correlate may be explained.

The lack of correlation among all the tests might be explained in part by the onset of anxiety during the period of the test. DeTakats (25) has mentioned adrenal stimulation, such as by anxiety or fear, as a cause of increased coagulability of the blood. In a few cases we have found marked acceleration of coagulation in lusteroid tubes and marked increase of heparin tolerance when the patients were on the verge of an anxiety attack or delirium tremens. Other factors, such as type of anesthesia, the presence of an occult infection, or the administration of barbiturates might explain the variations in clotting from patient to patient in the postoperative group. However, since all six tests were done within a space of two hours on each postoperative patient, these last factors could not very well explain the lack of correlation in the individual patient; i.e., these factors do not explain why some tests were normal and others abnormal in the identical patient at virtually the same time.

The prothrombin time of dilute plasma was less often abnormal than that of whole plasma. This was especially notable in the three thrombophlebitic patients, where the dilute plasma prothrombin time was normal in every instance, yet the whole plasma prothrombin time was shortened in all three. This finding is similar to that of Mahoney and Sandrock (26), who found a greater increase in prothrombin activity in their postoperative thrombophlebitis patients as shown by the test on whole plasma as compared to dilute plasma. Hurn, Barker, and Mann (27) also found that the prothrombin time of dilute plasma gave no more information as to hypercoagulability than the test as run on whole plasma. Tuft and Rosenfield (28) concluded that accelerated dilute plasma prothrombin determinations could not be used for prediction or diagnosis of thromboembolic disease. In contrast, Shapiro $(13,14,22)$ and Brambel and Loker (12) found the dilute plasma prothrombin time more sensitive to the state of hypercoagulability than the whole plasma prothrombin time.

Mahoney and Sandrock (26) found in their 58 normal postoperative patients a prolongation of the prothrombin time during the first three days following surgery. They found acceleration during this period only in those patients who subsequently developed thrombophlebitis. In our group, of 13 patients studied during the first three days postoperatively, none showed the prolongation of the whole plasma prothrombin time described by $\mathrm{Ma}$ honey and Sandrock (26). Further, the mean whole plasma prothrombin time in these 13 postoperative patients was 12.8 seconds, as compared with a mean of 13.5 seconds for the 28 controls. Among the 28 controls, the standard deviation for the whole plasma prothrombin time was $0.85 \mathrm{sec}$ onds. Among the 13 postoperative patients, the standard deviation for the whole plasma prothrombin time was 1.45 seconds. The standard error of the difference of the two means of 12.8 and 13.5 seconds was found to be 0.471 seconds. The observed difference was 0.70 seconds. This is not a significant difference.

Only one patient of this group of 29 postoperative patients developed thrombophlebitis after operation. The demonstration of frequent abnormalities in the six tests in so many of the 28 patients who did not subsequently develop thrombophlebitis would seem to indicate that none of these tests could be used to predict which patient is going to develop venous thrombosis following an operation. This statement is given weight by the fact that the only patient who did develop clinical thrombophlebitis showed no abnormality in any of the six tests which had been run five days previously.

It is thought worthy of comment that only one of the 27 patients having congestive heart failure showed an acceleration of coagulation in lusteroid tubes, and only two as measured by the three tube Lee-White test. This finding may be compared with that of Cotlove and Vorzimer (29) who found no shortening of the whole or dilute plasma pro- 
thrombin time in 20 patients with congestive heart failure. It is also of interest to note that 25 of our 27 patients were receiving digitalis therapy in maintenance doses, yet little evidence of acceleration of clotting was found. Digitalis has been frequently mentioned as an accelerator of clotting $(7,25,30)$. Ogura, Fetter, Blankenhorn, and Glueck (19) found some evidence of acceleration of coagulation in their patients as they were being digitalized, but found that this acceleration later disappeared in the majority, even though maintenance digitalis therapy was continued. Cotlove and Vorzimer (29) found that the administration of digitalis did not shorten the prothrombin time as determined on whole plasma or dilute plasma. Moses (31) found no change in heparin tolerance after the exhibition of digitalis. Flinn (23) found the Waugh-Ruddick test to show acceleration of coagulation after the administration of digitalis, but no acceleration was shown by the Lee-White test or by the prothrombin time on whole or dilute plasma.

\section{SUMMARY}

Twenty-nine postoperative patients were studied for evidence of accelerated coagulation. Nineteen showed acceleration by the Waugh-Ruddick test; ten showed acceleration in lusteroid tubes; six showed increased heparin tolerance; five showed shortening of the whole plasma prothrombin time; three showed shortening of the $12.5 \%$ plasma prothrombin time; three showed an acceleration by the modified Lee-White test.

The same tests were repeated on seven of these patients later in their postoperative courses and some showed persistence of hypercoagulability on the 12th postoperative day. The different tests did not correlate. The only patient who developed subsequent thrombophlebitis was normal to all tests. Three other patients with thrombophlebitis showed acceleration of coagulation in lusteroid tubes and shortening of the whole plasma prothrombin time. They were normal with regard to dilute plasma prothrombin time and the WaughRuddick test. Of 27 patients with congestive heart failure, 25 of whom were receiving digitalis, only one showed acceleration of coagulation in lusteroid tubes, and two showed acceleration in the LeeWhite test. Fourteen patients were given $25 \mathrm{mg}$. of heparin intravenously. Ten minutes later, blood samples were drawn almost simultaneously from the arm vein into which the heparin had been injected, and from a vein in the opposite arm. In six of these 14 patients, the clotting time was significantly longer in the blood sample taken from the vein receiving the heparin when compared to the blood obtained from the opposite arm.

\section{CONCLUSIONS}

1. Hypercoagulability of the blood is a frequent finding in the postoperative state, and may persist as long as 12 days after operation.

2. The correlation among the Waugh-Ruddick test, prothrombin time on whole plasma, prothrombin time on $12.5 \%$ plasma, lusteroid tube clotting time, and heparin tolerance test is poor, suggesting that they are concerned with different factors involved in the clotting process.

3. We could not predict which postoperative patients were going to develop venous thrombosis.

4. When performing the heparin tolerance test and similar tests in which a substance is injected intravenously, and a sample of blood is later drawn for analysis, it is advisable to draw the blood from the vein of the opposite arm. The vein into which the substance is injected probably retains a larger proportion of that substance than is found in the general circulation.

5. Of the tests studied, the Waugh-Ruddick heparin retarded coagulation test appears the most sensitive. Its lack of specificity, however, would seem to indicate that it is of no value in predicting or diagnosing thrombophlebitis.

\section{ACKNOWLEDGMENT}

The writer wishes to acknowledge the very kind assistance of Dr. Helen Glueck.

\section{BIBLIOGRAPHY}

1. Kadish, A. H., Coagulation of the blood in lusteroid tubes; a study of normal persons and patients with arterial or venous thrombosis. Am. Heart J., 1947, 34, 212.

2. Kadish, A. H., Coagulation time of the blood in lusteroid tubes: a study of patients receiving dicumarol. Am. Heart J., 1947, 34, 225.

3. Lozner, E. L., Taylor, F. H. L., and MacDonald, H., The effect of foreign surfaces on blood coagulation. J. Clin. Invest., 1942, 21, 241. 
4. Tocantins, L. M., Influence of contacting surface on coagulability and anticephalin activity of normal and hemophilic plasmas. Am. J. Physiol., 1945, 143, 67.

5. Jaques, L. B., Fidlar, E., Feldsted, E. T., and MacDonald, A. G., Silicones and blood coagulation. Canad. M. A. J., 1946, 55, 26.

6. Hirschboeck, J. S., The effect of operation and illness on clot retraction: description of a new method. J. Lab. \& Clin. Med., 1948, 33, 347.

7. Massie, E., Stillerman, H. S., Wright, C. S., and Minnich, V., Effect of administration of digitalis on coagulability of human blood. Arch. Int. Med., 1944, 74, 172.

8. Waugh, T. R., and Ruddick, D. W., A test for increased coagulability of the blood. Canad. M. A. J., 1944, 50, 547.

9. Waugh, T. R., and Ruddick, D. W., Studies on increased coagulability of the blood. Canad. M. A. J., 1944, 51, 11.

10. deTakats, G., and Gilbert, N. C., The response to heparin: a test of the clotting mechanism. J. A. M. A., 1943, 121, 1246.

11. Hagedorn, A. B., and Barker, N. W., Response of persons with and without intravascular thrombosis to a heparin tolerance test. Am. Heart J., 1948, 35, 603.

12. Brambel, C. E., and Loker, F. F., Significance of variations of prothrombin activity of dilute plasma. Proc. Soc. Exper. Biol. \& Med., 1943, 53, 218.

13. Shapiro, S., Hyperprothrombinemia, a premonitory sign of thromboembolization (description of a method). Exper. Med. \& Surg., 1944, 2, 103.

14. Shapiro, S., Sherwin, B., Redish, M., and Campbell, H. A., Prothrombin estimation; procedure and clinical interpretations. Proc. Soc. Exper. Biol. \& Med., 1942, 50, 85.

15. Lee, R. I., and White, P. D., A clinical study of the coagulation time of the blood. Am. J. M. Sc., 1913, 145, 495.

16. Quick, A. J., Rene, H. C., and Stefanini, M., The value and limitations of the coagulation time in the study of the hemorrhagic diseases. Blood, 1948, 3, 1120.

17. Quick, A. J., The nature of bleeding in jaundice. J. A. M. A., 1938, 110, 1658.

18. Whittaker, J., The effect of temperature on the
Waugh and Ruddick test for increased coagulability of blood. Canad. M. A. J., 1945, 52, 185.

19. Ogura, J. H., Fetter, N. R., Blankenhorn, M. A., and Glueck, H. I., Changes in blood coagulation following coronary thrombosis measured by the heparin retarded clotting test (Waugh and Ruddick test). J. Clin. Invest., 1946, 25, 586.

20. Potts, W. J., and Pearl, E., Study of platelet count and coagulation time of plasma and whole blood following operation. Surg., Gynec., \& Obst., 1941, 73, 492.

21. Dawbarn, R. Y., Earlham, F., and Evans, W. H., The relation of the blood platelets to thrombosis after operation and parturition. J. Path. \& Bact., 1928, 31, 833.

22. Shapiro, S., Sherwin, B., and Gordimer, H., Postoperative thrombo-embolization. Ann. Surg., 1942, $116,175$.

23. Flinn, J. H., The effect of digitalis on the coagulability of blood. Proc. Cent. Soc. Clin. Research, 1948, 21, 100.

24. Best, C. H., and Jaques, L. B., Heparin in blood clotting and thrombosis. Ann. N. Y. Acad. Sciences, 1948, 49, 501 .

25. deTakats, G., Thromboembolism. Minn. Med., 1945, 28, 843.

26. Mahoney, E. B., and Sandrock, R. S., The early recognition of post-operative venous thrombosis. Bull. N. Y. Acad. Med., 1948, 24, 636.

27. Hurn, M., Barker, N. W., and Mann, F. D., Variations in prothrombin and antithrombin in patients with thrombosing tendencies. Am. J. Clin. Path., 1947, 17, 709.

28. Tuft, H. S., and Rosenfield, R. E., Significance of the accelerated reaction in determination of prothrombin time of diluted plasma. Am. J. Clin. Path., 1947, 17, 704.

29. Cotlove, E., and Vorzimer, J. J., Serial prothrombin estimations in cardiac patients: diagnostic and therapeutic implications; use of dicumarol. Ann. Int. Med., 1946, 24, 648.

30. deTakats, G., Trump, R. A., and Gilbert, N. C., The effect of digitalis on the clotting mechanism. J. A. M. A., 1944, 125, 840.

31. Moses, C., The effect of digitalis, epinephrine, and surgery on the response to heparin. J. Lab. \& Clin. Med., 1945, 30, 603. 